\title{
The Use of NVivo in the Different Stages of Qualitative Research
}

\author{
Carmen Trigueros-Cervantes ${ }^{1}$, Enrique Rivera-García ${ }^{1}$, Irene Rivera Trigueros ${ }^{2}$ \\ ${ }^{1}$ Universidad de Granada, Facultad de Ciencias de la Educación, Campus de Cartuja s/n, \\ 18071 Granada, España \\ ${ }^{2}$ Universidad de Granada, Facultad de Comunicación y Documentación, Colegio Máximo \\ de Cartuja, 18071 Granada \\ \{Carmen Trigueros-Cervantes, Enrique Rivera-García, Irene Rivera-Trigueros \\ ctriguer\}@ugr.es
}

\begin{abstract}
When researchers take their first steps in qualitative research, they face the great lack of models to follow regarding the method to use in the analysis of data, on some occasions falling into the temptation of coveting the high level of systematisation employed by researchers working with quantitative data. This article offers a basic theoretical contribution that allows researcher to approach qualitative data analysis and the use of the NVivo software, highlighting its advantages and describing the main functions at each moment of a qualitative investigation, placing particular emphasis on the analysis process.
\end{abstract}

Keywords: NVivo; software use; qualitative methodology; data analysis; analysis process.

\section{Introduction}

CAQDAS NVivo - from a holistic perspective - not only provides help in information or data analysis, its usefulness covers the entire process of a qualitative investigation. From a very generic point of view, qualitative research can be understood as "localised activity in a certain place and time that situates the observer in the world" [1, p.48]. Its intention is to make the world visible thanks to interpretive practices and the use of a series of materials that are going to be particular to it such as observation, narration, interviews and the analysis of textual, digital or audiovisual documents. Furthermore, its habitat or research context will be natural settings, which involves us approaching the phenomenon that is the object of our study with an open vision, attempting to interpret them from the very words and actions of the people participating in the research process.

The open view previously described means that researchers may be moving in a wide spectrum, allowing the coexistence of paradigms within it that can go from the positivist or post-positivist, based on Grounded Theory and deductive logic, which will situate its narrative in the mould of the scientific report, to the socio-critical, represented by many sides, but all of them identifying critical theory as a foundation of a type of report removed from the scientific model, and which may become expressed in the form of an essay, story, fable, historical, economic or sociocultural analysis, or autobiography [2].

This is a post-peer-review, pre-copyedit version of an article published in the book Computer Supported Qualitative Research. The final authenticated version is available online at: https:/doi.org/10.1007/978-3-319-61121-1_32. 
With this panorama described in mind, perhaps the question that we would have to ask is whether CAQDAS NVivo is able to provide an answer to the wide diversity described or whether, on the contrary, it is not designed to respond to all of them. The answer is easy: the software is simply a tool put at the disposal of researchers. It doesn't determine or obstruct the paradigm or methodology along which we move. This decision will always depend on the researcher, based on the ideological, epistemological, ontological and methodological position, but not forgetting that qualitative methodology normally occurs when multiple methods are employed to [3], [4] search for a better understanding of the phenomenon that is the object of our study.

More than a tool, CAQDAS NVivo is a complete bank of work put at the disposal of the "qualitative bricoleur". This concept, widely used in the field of qualitative research [5]-[7], offers us an extremely graphic idea of the versatility with which researchers can move when carrying out their work. The availability of an excellent bank of work is not a guarantee of success. The true guarantee of its quality will be the artisan who, with wisdom, will have known how to select the appropriate tool from the bank to carry out his work. What we can guarantee is that we are facing software which, in good hands, can help us greatly in our investigative process.

If we specify that which has been put forward to this point, we find that, when facing a qualitative investigation, we will have to opt for one tool or another depending on the point of the paradigmatic spectrum where we are situated, and despite being at risk of not being able to include the multitude of tendencies and focuses that could arise, we can identify four important tasks to carry out:

1. Research design. The researcher must contextualise the experience to be studied. It is the moment to decide the most appropriate methodology and affirm our beliefs on the basis of the paradigm that sustains us.

2. Data production and analysis. It will be the task par excellence of the researcher, tackled from the rigorousness of a selective display or from the amplitude that allows us to initiate production from an informant or key context. It will be possible to adopt an inductive, deductive or mixed focus. The end point will be to achieve the understanding of the phenomenon studied, affording it visibility.

3. Identification of existing theories. Prior theories may determine the production of data or theories gathered from the inductive production and analysis. In both cases other versions of the phenomenon that is the object of our study should not be ignored.

4. Report construction. This last task is key in the process. The focuses can be many and their production will be orientated based on the audience that the report is aimed at. If we want to emphasise that the qualitative research is understood as a process of improvement, the reports should be indebted to the people who have participated in the process, independently of whether we can also create reports to provide a response to audiences of a more academic and/or scientific nature. 


\section{NVivo in research design}

Research design, as put forward by Cheek [8], should cause the researcher to become aware of the context in which it is going to develop. Up to this point there was always the myth that qualitative research could be carried out at low cost or with no funding whatsoever, but the current reality tells us that all research requires funding for two fundamental reasons: being able to cover the costs it implies, and promote the work carried out. This necessity can mean we are obliged to sacrify our axiological and methodological beliefs and approaches in order to adapt ourselves to the dominant culture in the sphere of research.

Once this clarification has been realised (we recommend [8], p. 53-93), Denzin \& Lincoln [9] establish five levels of research and reflection when setting out the design of an investigation:

1. Where is our paradigm of reference going to be in terms of the context, participants, method, production techniques and data analysis? In short, the paradigm and the process to follow must be specified for the sake of its consistency.

2. Are the materials (methods and techniques) going to be appropriate for providing a response to the problems contemplated and the change we wish to produce?

From these two initial questions, the rest are going to open the door for us to the social phenomenon that we are going to investigate.

3. What is our object of study going to be? Materialised in the queries (orienting objects or possible hypothesis, according to our paradigm of reference) and the people or phenomena that we will attempt to view from the investigation. This question will be answered with a greater or lesser degree of flexibility, according to our paradigmatic positioning. Situated in the positivist/post-positivist side, it will be necessary to explain internal and external criteria of validity, and the utilisation of sample selection techniques. If we place ourselves on the opposite side, or the social-critical paradigm in any of its manifestations, where before we found an absolute rigidity, now we enjoy maximum flexibility when carrying out and putting into practice the design of the investigation.

The study object determines a perspective with which a phenomenon is tackled, and as such, it is a problematic reasoning of reality, [10]. Analysing and studying reality does not consist in the recollection of empirical data, rather, it is the construction of data from a specific viewpoint, which is related to what has been denominated, that is, the theoretical, political and ethical view and position, [11] which will be specified in the principles of actuation and the methodological option.

4. What strategies are going to be appropriate to provide an answer to the object of study? Before continuing, it is worth clarifying the difference between methodology and method. The methodology is the philosophical framework or the way of thinking and studying social reality, whereas the method is the group or procedures and techniques for producing and analysing data [12], [13]. There are a wide range of methods available to us and, from the coherence with the previous reflections, we will have to opt for the one or ones that can provide us with the best answer. We can become social or educational ethnographers; Case Study researchers; interpreters of social phenomena in their multiple manifestations; analysts of reality from logical-deductive strategies, applying Grounded Theory; active participants of investigation focusing on action, technique or critique, or 
focus ourselves on a clinical qualitative research model centred on the questions that arise from daily practice different contexts, including health, education, and social action.

With the previous matters answered, we reach the last question:

5. Which research tools or techniques are we going to select from our bank of work to provide a response to the queries generated? We can basically group them into four large areas: observational, documental, narrative and dialogical. On some occasions it will be necessary to opt for one and on others a combination will be necessary if our queries want to go further than knowing the what to look into the how, where and why of our investigation. Quality is not always found in the quantity or diversity of techniques or participants; sometimes we discover it in the study of the singular, although it is translated into one participant and a single technique. Excellent autoethnographies demonstrate it thus (we recommend [14, p. 262-315].

Quivy \& Van Campenhoudt [15], in their design proposal for a qualitative investigation, open two basic demands for the tackling of this first step in our research: self-reflection and the consultation of external sources.

How can the NVivo software help us in these two processes?

To begin the self-reflection process our first decision should be to create a new NVivo project. This decision, which may seem obvious, is not usually made by the majority of researchers, who consider the program to be exclusively a data analysis tool.

From here, it is the moment to work with the internal sources, and within these we have a key tool designed to gather together implicit beliefs and theories, both prior and constructed throughout the process by the researcher; we are talking about memos, which are still nothing more than editable text documents which allow us to collect all reflections and notes that could be relevant to the investigation. The way of organising them in different folders or subfolders is for the researcher to decide. To summarise, we could say that memos would be the equivalent of the researcher's diary.

As a complementary tool to the memos, and seeking a better understanding and comprehension of the social phenomenon we are going to study, CAQDAS NVivo within the Explore menu - supplies us with the mind and concept maps. In the first case it helps us create, via a hierarchical and ramified structure, a conceptual scheme of the design elements of our investigation. In the second case, we are able to generate a freely designed map that is not necessarily hierarchical, in which original ideas and concepts can be combined with elements already generated in our project (resources, nodes, classifications, ...). This second possibility of creating deductive maps allows the establishment of relationships and inferences between the ideas and queries of the researcher, and the theories constructed by the participants, reflected in the categories (nodes) created in the analysis.

Regarding the consultation of external sources, they can be produced in different intensities based on the paradigm that supports the investigation. From positivist and post-positivist approaches, it will be a key task to undertake upon starting our investigation, and with a great degree of depth, as we will prioritise deductive over inductive analysis processes. If, on the other hand, our investigation is framed within the constructivist or socio-critical paradigm, the stress will be on the voice of the participants, their theories and beliefs, to which, in this case, from the inductive 
processes, the approach to already constructed external or formal theories will be progressive and simultaneous with the emergence of the implicit theories of the participants.

In both cases, CAQDAS NVivo offers us a series of tools that we are going to find very useful for the documentation process. At this point we are going to focus on the two most common which are currently at our disposal: paper and digital documents. For the former, the tool available is the external, which is a bibliographical record of those resources that cannot be included in our project as an internal. The externals are going to be equivalent to the bibliographical records or summaries that are usually made when we want to document a research project. The advantage is in the fact that, being incorporated into the project, they are available for categorisation and codification in the same way as any other resource (internal or memo).

In the event that the documental source is in digital format and is compatible with the software, the possibilities for its management increase. In a logical, ideal situation, the steps to carry out would be as follows:

1. Carry out a search for books, articles or any other document via the different databases to locate relevant information on the topic that interests us.

2. Use any of the bibliographical reference managers available and which NVivo subsequently recognises to import the information it generates (EndNote, Mendeley, RefWorks and Zotero).

3. From the previous step, NVivo import all of the information generated, organising it in the project automatically via the option of the Data, other sources menu, selecting the management system used (EndNote, Mendeley, RefWorks and Zotero).

Within the queries to external sources, Quivy \& Van Campenhoudt [15] mention the convenience of holding interviews with experts on the topic with the goal of specifying it. These documentation interviews can be totally or partially transcribed (only fragments of value) in CAQDAS NVivo. In this case, the recording should be made in audio or video for the file to then be incorporated into the project file from the option that it offered to us in the Data menu, and proceed to its transcription. If we do not wish to lose the link to the audio or video file, we would have to create it as an external; in the event that we are only interested in the interview text, we could transcribe directly to a memo.

Lastly, with a view to a more in-depth reading of the texts, and seeking to make the opinions, questions or theories of the researcher visible, we could use the link options within the Analyze menu, and it should be pointed out that from these we can incorporate notes in the texts analysed, which bring together ideas or reminders, "see also" links to establish relationships between documents, hyperlinks to external files or documents available on the internet and, finally, create links to memos with the document that we are analysing. In figure 1 we can see a summary of the strategies that can be used at this first design stage of the investigation. 


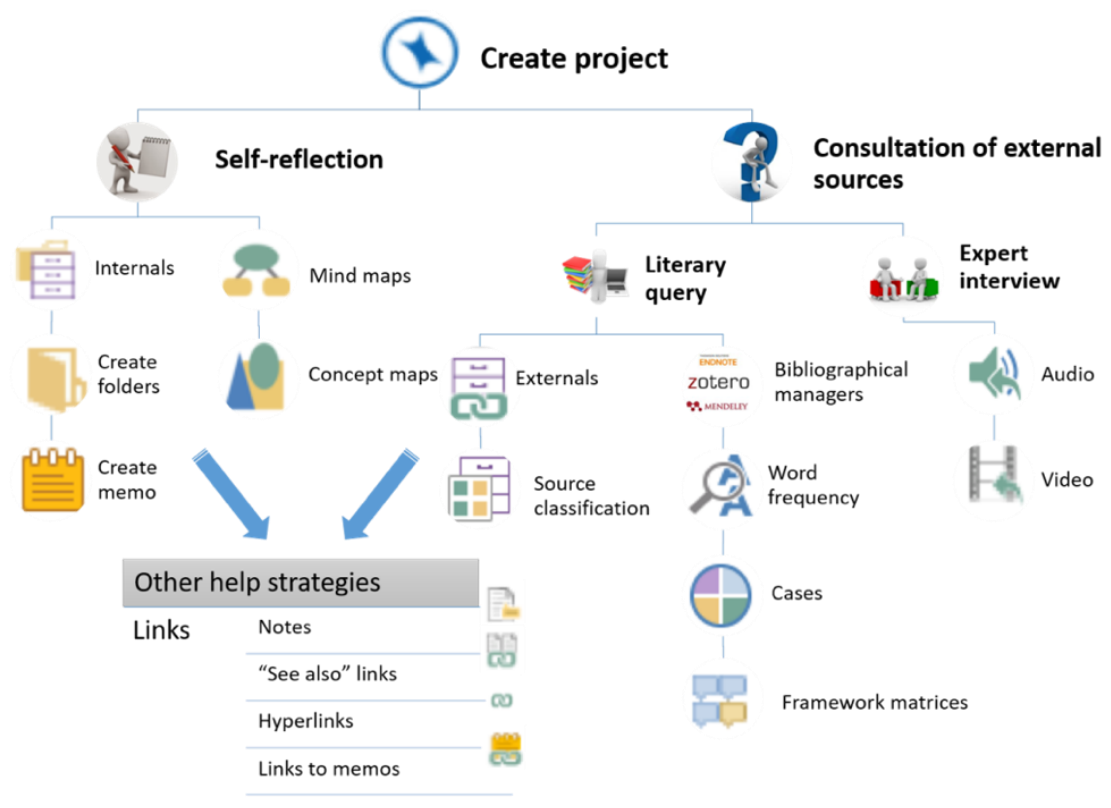

Fig. 1. NVivo strategies in qualitative research design

\section{NVivo in data production and analysis}

How is data production and analysis carried out? In the arc that we drew at the beginning of this article we saw how qualitative research moves in a wide paradigmatic spectrum; the reality of the situation is that there are production and analysis focuses that are very far apart and even opposing, despite sharing a single cohesive concept. If we take a global approach to tackling the problem and, at the risk of being dichotomous, we can start out from two models:

In the first, again taking the principles of experimental design of the Sciences, we find ourselves before two clearly defined moments: data collection and analysis. The qualitative investigations that are nourished by it normally identify some participants (really a sample), intentionally selected, which looks for representation. It is frequent to observe in the designs an initiation from previous theories, making the act of data production the purely mechanical act of creating a preset number of observations, interviews, focus groups and any other information collection technique. That is, the stress in deduction rather than induction, and there is usually preference for an analysis that tends to work from the particular, depersonalising the participants, in order to generate or test a general theory.

In this second model, we can see that it is the singular that is important, the participant, from whom we will construct the substantive theory from his or her own implicit theories. The start of the data production is generated from a key informant. 
The process is transformed into a productive spiral, fed back from an exercise of constant to-ing and fro-ing from analysis to production. This constant game which, as in the Moebius strip, never has a beginning or end, will stop when the researcher decides that the knowledge generated on the social phenomenon studied is sufficiently relevant to take the context as saturated (see figure 2).

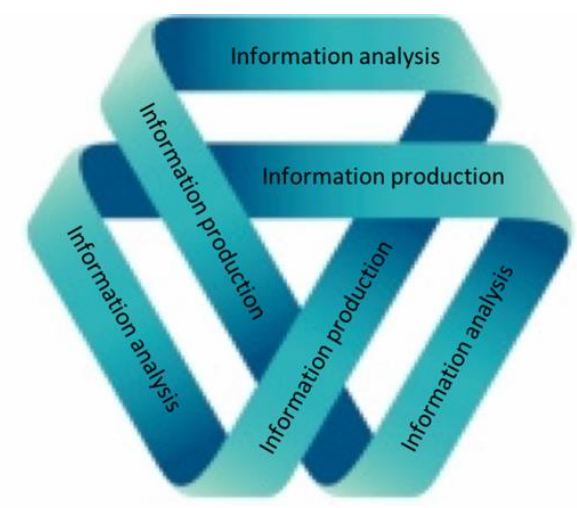

Fig. 2. Process of analysis in an emerging qualitative research design

What can NVivo contribute to facilitate data production and analysis to the researcher? (See figure 3) Economy, credibility and quality of our investigation.

Economy, because it facilitates the most arduous tasks of qualitative research, especially the identification of central categories and subcategories, and their subsequent codification. It is convenient to unify concepts to avoid confusion. The software identifies the category as a node. This concept is more appropriate for as, as it breaks the classic linearity, and encourages working from the reconstruction of the discourses, by way of the weaving of a network. In this way, we can habitually read how the codification assimilates the indexing concept, used more in the sphere of the digital network and understood as the incorporation of content to an index (nodes). As well as these tasks, it will allow us to carry out specific text searches, classify the participants, assign attributes, construct framework matrices that facilitate discourse analysis, etc.

The second contribution is credibility. One of the main criticisms aimed at qualitative research is its lack of rigour in analysis processes. It is frequent to see how in a report the methodological path carried out is not shown, in many cases, a sensation in which the reader does not know if the theories of the participants prevail, or the specific view the researcher is makes of them. We are not ingenuous; asepsis in the qualitative report does not exist, nor is it recommendable if we put forward that the truth is polyhedral and depends on the angle from which it is observed. But from this point to not leaving evidence of the analysis process carried out there is an abyss that we cannot allow. This credibility can be made visible with CAQDAS NVivo through the use of different query options such as matrix coding, coding, compound, word frequency, etc. 
The consultation strategies that are going to be employed will also depend on the paradigm within which we are positioned in our investigation, and the method or techniques we are using to produce the information.

Lastly, we will find the third contribution of the NVivo software in the improvement of the overall quality of the investigation. We can still find, in the 21 st century, colleagues who defend the purity of qualitative research tooth and nail against the attacks it is receiving from the world of technology. We simply have before us a tool (we consider that in the face of all it is a work bank) and the decisions of how, when and for what to use it will always be in the hands of the researcher.

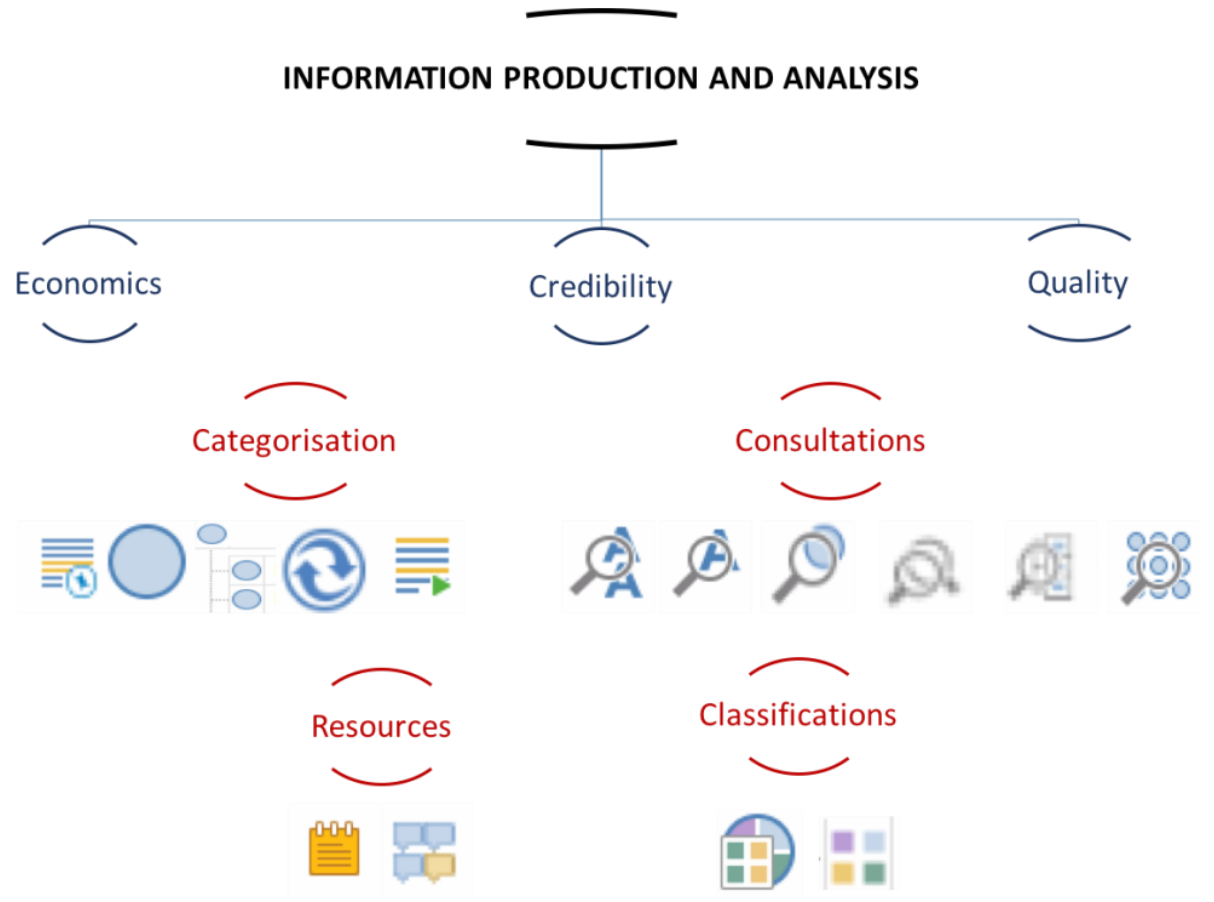

Fig. 3. NVivo strategies in data production and analysis

What is evident is that a greater depth in the data produced, the possibility of establishing relationships between the whats, the whys, the hows and the whens, the possibility of growing the singular into the particular from the identification of attributes, polishing the analysis from the construction of matrices or being able to carry out a comparison of the discourses of the participants, leaving evidence from the framework matrices, means an improvement in the quality of the investigation. 


\section{NVivo in the identification of existing theories}

The critical stage in the creation of qualitative research reports occurs at the moment when we have to move from the description of participants' theories to their fusion with the interpretation made by the researcher from them, constructing the substantive theories of the investigation. We are used to linear reports which imitate the design of an experimental report and respect its big moments, but which are camouflaged by the qualitative terminology. Instead of the state of the question, on the majority of occasions there is a non-critical superposition of the dominant theory in the field. From this point, we move on to the exposition of a methodology that, on occasions, lacks even modesty and maintains concepts such as sample, subjects, study variables, research hypothesis; it is rare to find starting questions which, if they do appear, are more often than not accompanied by objectives that are usually repetitions of the former, defined from respect for established guidelines. The next step is to put forward some results that, in general, are limited to a descriptive sequence of the categories, constructed via the summation of a constant cycle of textual quotes followed by the explanation of the researcher, which is saying the same thing with other words. There is then a discussion, disguised as an interpretation of results, in which formal theories put forward in the initial question stage cross with the substantive theories constructed with the participants, to end with some conclusions that focus on the most significant aspects of the investigation.

Against this model it should also be pointed out that there are excellent investigations which, starting out from the questions and motivations that led to the beginning of the study, open the range from a mixed analysis, in which substantive theories emerged crossed with the dominant ones in the field, and an excellent incorporation of the paths followed to reach the described destination. Notwithstanding, it must be said that these are in the minority.

How does NVivo help us in this process? Putting at our disposal a wide range of tools, which gives us the power to test the questions that will be generated throughout the analysis process. We can generally find this range of tools in three spaces in the program in the main menus: Analyze, Consult and Explore (see figure 4).

From the Analyze menu, once the main categories (nodes) have been examined, we continue with categorisation searching for and establishing relationships (associative, unidirectional or bidirectional) between these categories and analysing those that CAQDAS NVivo calls feelings, which collect emotions or aspects that are very positive, positive, negative and very negative in relation to the content of each node.

The Query menu opens all of the tools that allow us to carry out different search strategies and matrix coding.

Lastly, the Explore menu provides us with the possibility of creating maps, which can be mind maps, of projects maps or concept maps; the possibility of carrying out approximations of visual analyses in the following formats: chart; hierarchy chart; cluster analysis; comparison diagram and network sociogram. The only thing that the software does not give us is creativity, imagination, intuition, curiosity and evidence that all researchers need to undertake the deductive processes of the analysis. 


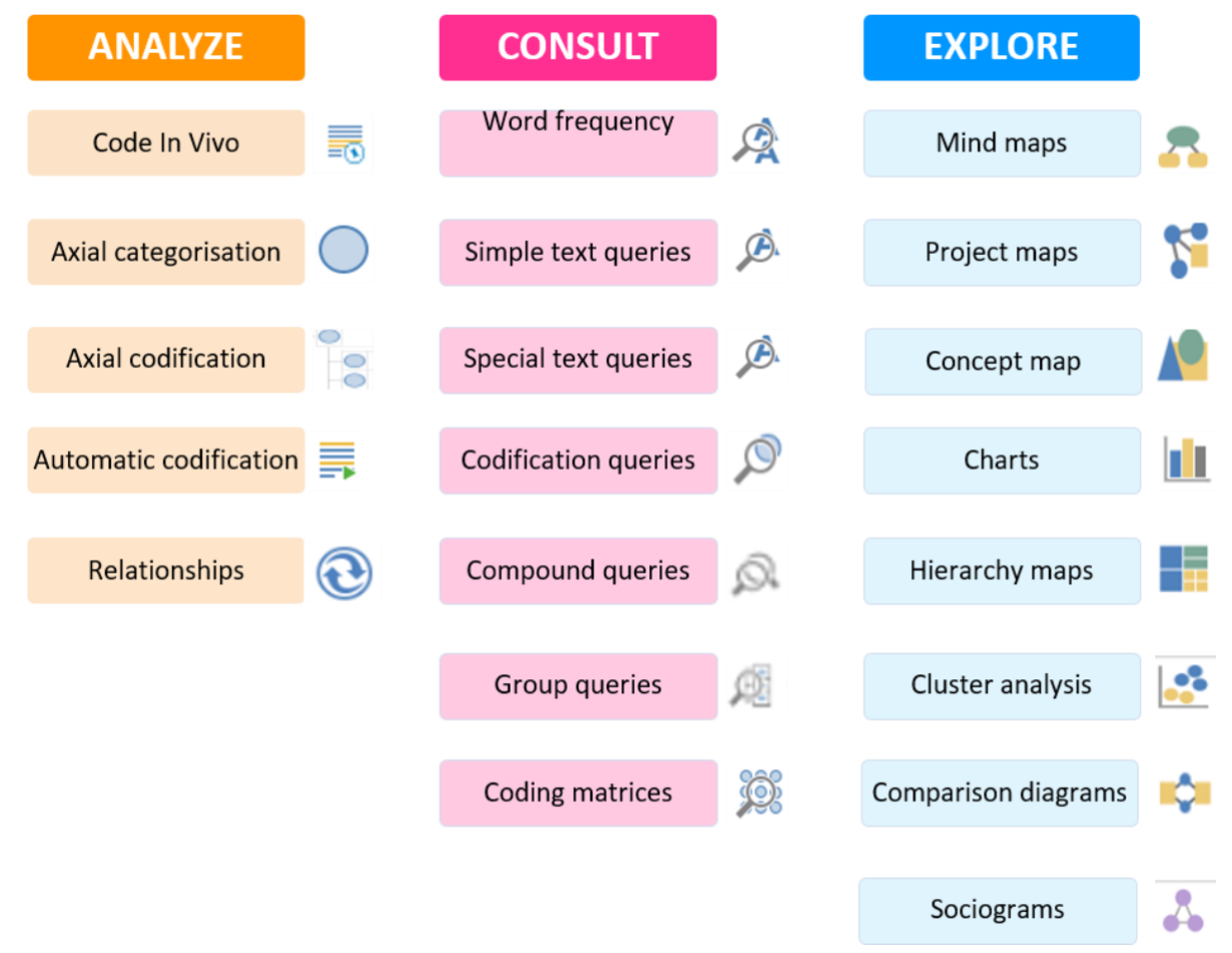

Fig. 4. NVivo strategies in the identification of existing theories

\section{NVivo in the creation of a report}

Once this point has been reached it is complex to be able to go deeper without reiterating the aforementioned points if we want to draw attention to the convenience of the change of mentality that should operate in our community of qualitative researchers. Despite this, as we mentioned in the previous section, we have taken the clothes of experimental designs off. Few take risks, except in the field of anthropology, to offer report proposals that are more coherent with the principles that govern the qualitative. We understand and respect that the spectrum we operate in is wide, and in many cases there are more discrepancies than agreements between researchers which, in theory, we move in the same ecosystem as qualitative research. But it would be necessary to start plotting out limits to the idea of "everything goes" as a report. Still respecting that carrying out qualitative research contains a part of significant artistic creation and that the type of reports is and should be diverse, we must start establishing some minimum guidelines that strengthen the paradigm and afford it the credibility and quality demanded of us from other fields of knowledge.

In this space CAQDAS NVivo provides us with the possibility of incorporating all types of graphic images that facilitate the understanding of the processes carried out. In addition, it permits us to generate maps, already mentioned, which serve to provoke a 
more agile and quick understanding of the contributions made. Furthermore, its complete compatibility with Office allows us, via copy and paste strategies, to be able to bring any information produced with the program to our word processor or spreadsheet. This path is bi-directional, to which it works perfectly in the opposite sense. It also allows us to export reports in PDF format, or images that we can then include in a document generated with the word processor, to create the research report.

\section{Conclusions}

Simplifying the possibilities of CAQDAS programs - especially NVivo - is one of the most common errors of qualitative researchers, even leading to their denial from a position that we could now label as classical. Denying the benefit of making use of the technological advances that facilitate the qualitative research process is to take a position of denial that is, today, sterile and useless, which would not permit us to make advancements in the important aspects.

We should be very aware that under no circumstance do current CAQDAS programs, especially NVivo, which we understand to be the most useful of those in existence, attempt to substitute the researcher. The questions of the before and the during of the investigation, access strategies and information production are functions that we cannot delegate to the program. However, we do find within it the help that facilitates the processes, the detailing of the analysis and the offering of the evidence that will give the investigation a greater quality.

The software is simply a tool put at the disposal of researchers, and the uses and risks that may exist around the use of information technology in qualitative research do not originate from the nature of the program itself, rather from the attitudes of the researchers; thus, NVivo conditions the ideological, epistemological, ontological and methodological positioning of an investigation.

\section{References}

1. Denzin, N. k., \& Lincoln, Y. S.: Introducción General. La Investigación Cualitativa como Disciplina y como Práctica. In: N. k. Denzin \& Y. S. Lincoln (Eds.) El Campo de la Investigación Cualitativa, vol. 1, pp. 43--116. Barcelona, Gedisa. (2011)

2. Guba, E. G., \& Lincoln, Y. S.: Controversias Paradigmáticas, Contradicciones y Confluencias Emergentes. In: N. K. Denzin \& Y. S. Lincoln (Eds.) Paradigmas y Perspectivas en Disputa. Manual de Investigación Cualitativa, vol. 2, pp. 28--72. Barcelona, Gedisa. (2012)

3. Flick, U.: An introduction to Qualitative Research. London, SAGE Publications. (2002)

4. Maxwell, J. A., \& Chmiel, M.: Notes Toward a Theory of Qualitative Data Analysis. In: U. Flick (Ed.) The SAGE Handbook of Qualitative Data Analysis, pp. 21--34. London, SAGE Publications, https://doi.org/10.4135/9781446282243 (2014)

5. Becker, H. S.:Tricks of the Trade: How to Think About your Research While You're Doing It. Chicago, University of Chicago Press. (1998) 
6. Harper, D. A.: Working Knowledge: Skill and Community in a Small Shop. Chicago, University of Chicago Press. (1987)

7. Weinstein, D., \& Weinstein, M. A.: Georg Simmel: Sociological Flaneur Bricoleur. Theory, Culture \& Society, vol. 8, pp. 151--168. (1991)

8. Cheek, J.: La Práctica y la Política de la Investigación Cualitativa Financiada. In: N. k. Denzin \& Y. S. Lincoln (Eds.) Las Estrategias de Investigación Cualitativa. Manual de Investigación Cualitativa, vol. 3, pp. 52--93. Barcelona, Gedisa (2013)

9. Denzin, N. K., \& Lincoln, Y. S.: Introducción al Volumen III. Estrategias de Investigación. In: N. K. Denzin \& Y. S. Lincoln (Eds.) Las Estrategias de Investigación Cualitativa. Manual de Investigación Cualitativa, vol. 3, pp. 33--51. Barcelona, Gedisa. (2013)

10. Zemelman, H.: Conocimiento y Sujetos Sociales. Contribución al Estudio del Presente. La Paz (Bolivia): Instituto Internacional de Integración del Convenio Andrés Bello (IIICAB), http://www.vicepresidencia.gob.bo/IMG/pdf/zemelman-2.pdf (2011)

11. Tello, M. C.: The Object of Study in Social Sciences: Between Question and Hypothesis. Cinta de Moebio. Revista Electrónica de Epistemología de Ciencias Sociales, vol. 42, pp. 225--242, http://www.moebio.uchile.cl/42/tello.html (2012)

12. Strauss, A., \& Corbin, J.: Bases de la Investigación Cualitativa: Técnicas y Procedimientos para Desarrollar la Teoría Fundamentada. Medellín, Universidad de Antioquia. (2002)

13. Van Manen, M.: Investigación Educativa y Experiencia Vivida. Barcelona, Idea Boocks. (2003)

14. Holman, S.: Autoetnografía. In: N. k. Denzin \& Y. S. Lincoln (Eds.) Métodos de Recollección y Análisis de Datos. Manual de Investigación Cualitativa, vol. 4, pp. 262-317. Barcelona, Gedisa. (2015)

15. Quivy, R., \& Van Campenhoudt, L.: Manual de Investigación en Ciencias Sociales. México, Noriega. (2000) 